\title{
Subject Identifier
}

National Cancer Institute

\section{Source}

National Cancer Institute. Subject Identifier. NCI Thesaurus. Code C83083.

A sequence of characters used to identify, name, or characterize the study subject. 